\title{
Adubação nitrogenada e intervalos de colheita na produtividade e nutrição da erva-mate e em frações de carbono e nitrogênio do solo
}

\author{
Nitrogen fertilization and harvesting intervals affect yerba mate productivity \\ and the nitrogen and carbon of soil
}

\section{Delmar Santin ${ }^{\mathrm{I}}$, Eliziane Luiza Benedetti ${ }^{\mathrm{II}}$, Nairam Félix de Barros ${ }^{\mathrm{III}}$, Igor Carvalho de Almeida ${ }^{\mathrm{IV}}$, Guilherme Ferreira Simiqueliv, Júlio César Lima Neves ${ }^{\mathrm{VI}}$, Ivar Wendling ${ }^{\mathrm{VII}}$, Carlos Bruno Reissmann ${ }^{\mathrm{VIII}}$}

\begin{abstract}
Resumo
$\mathrm{Na}$ erva-mate (Ilex paraguariensis) o principal produto colhido é composto por folhas (FO) e galhos finos (GF), resultando em elevada exportação de nutrientes, dentre eles o N. As informações técnico-científicas disponíveis para subsidiar uma recomendação da adubação nitrogenada racional são insuficientes, o que põe em risco a sustentabilidade da produção, especialmente se as colheitas são mais intensivas. Por isso, objetivou-se avaliar a influência da adubação nitrogenada e do intervalo de colheita no teor de $\mathrm{N}$ e carbono orgânico $(\mathrm{CO})$ do solo, na produtividade e no estado nutricional da erva-mate. O experimento foi instalado em São Mateus do Sul - PR, em erval com sete anos e meio de idade, estabelecido em Latossolo Vermelho Distrófico, no qual se avaliaram doses de 0,20,40,80, 160 e $320 \mathrm{~kg} \mathrm{ha}^{-1}$ de $\mathrm{N}$, para intervalos de colheita de 12, 18 e 24 meses. Os teores de $\mathrm{N}$ e CO do solo, nas formas lábil (NL e COL) e total (NT e COT), foram determinados nas profundidades de 0-10, 10-20 e 20-40 cm. A colheita consistiu na remoção de aproximadamente $95 \%$ da copa que brotou da colheita anterior. A massa verde colhida foi determinada individualmente para os componentes $\mathrm{FO}$, GF e galho grosso (GG), sendo FO+GF correspondente à ervamate comercial (ECOM). Avaliou-se, também, a relação entre massa verde/seca (MV/MS) e o teor de $\mathrm{N}$ na FO, GF e GG. O efeito positivo da adubação nitrogenada no teor de NL e COL do solo foi mais expressivo no menor intervalo de colheita e negativo ou nulo para o intervalo de 24 meses. As doses de $\mathrm{N}$ aumentaram o teor de NT nos maiores intervalos de colheita e reduziram para colheita de 12 meses e o COT não foi influenciado pela adubação. Houve aumento da produtividade com as doses de $\mathrm{N}$, e as respostas mais expressivas ocorreram nos maiores intervalos entre colheitas. Intervalo de 12 meses entre colheitas é insuficiente para a planta recuperar-se do impacto causado pela colheita. O intervalo de 18 meses é o mais recomendável, desde que a planta esteja bem nutrida em $\mathrm{N}$. A adubação nitrogenada não influencia o teor de água na erva-mate comercial verde, sendo esta dependente do intervalo de tempo entre colheitas. Teor foliar de $\mathrm{N}$ entre 33,0 e $37,0 \mathrm{~g} \mathrm{~kg}^{-1}$ pode indicar plantas bem nutridas, independentemente do intervalo de colheita.
\end{abstract}

Palavras-chave: Ilex paraguariensis; Eficiência de utilização do nutriente; Manejo de colheita; Matéria orgânica do solo

\section{Abstact}

Leaves $(\mathrm{FO})$ and thin branches $(\mathrm{GF})$ are the main plant components harvested from Ilex paraguariensis

\footnotetext{
Engenheiro Florestal, Dr., Pesquisador Autônomo, Rua Pedro dos Santos Corrêa, 75, CEP 89464-244, Alto da Tijuca, Canoinhas (SC), Brasil. desantinflorestal@yahoo.com.br (ORCID: 0000-0001-9006-3109)

II Engenheira Agrônoma, Dra., Professora do Instituto Federal de Santa Catarina, Av. Expedicionários, 2150, CEP 89466-312, Campo da Água Verde, Canoinhas (SC), Brasil. eliziane.benedetti.@ifsc.edu.br (ORCID: 0000-0002-4944-3369)

III Engenheiro Florestal, Ph.D., Professor Titular, Departamento de Solos, Universidade Federal de Viçosa, CEP 35670-900, Viçosa (MG), Brasil. nfbarros@ufv.br (ORCID: 0000-0001-7081-2619)

IV Engenheiro Agrônomo, Pesquisador Autônomo, Praça Ministro Gabriel Passos, 114202, CEP 36300-000, São Tiago (MG), Brasil. igor.almeida@ufv.br (ORCID: 0000-0002-4277-7294)

Engenheiro Florestal, MSc., Doutorando em Genética e Melhoramento, Departamento de Estatística, Universidade Federal de Viçosa, CEP 35670-900, Viçosa (MG), Brasil. guisimiqueli@gmail.com (ORCID: 0000-0002-2867-0255)

vı Engenheiro Agrônomo, Dr., Professor Associado, Departamento de Solos, Universidade Federal de Viçosa, CEP 35670-900, Viçosa (MG), Brasil. julio_n2003@yahoo.com.br(ORCID: 0000-0001-8356-5100)

VII Engenheiro Florestal, Ph.D., Pesquisador, Embrapa Florestas, Estrada da Ribeira, km 111, Parque Monte Castelo, CEP 83411-000, Colombo (PR), Brasil. ivar.wendling@embrapa.br (ORCID: 0000-0002-1008-6755)

VIII Engenheiro Florestal, Ph.D., Professor Sênior, Departamento de Solos e Engenharia Agrícola, Rua dos Funcionários, 1540, Juveve, CEP 80035-020, Curitiba (PR), Brasil. reissman@ufpr.br (ORCID: 0000-0002-9867-8025)
} 
(mate) plantations, leading to high exportation of nutrients, among them, the nitrogen $(\mathrm{N})$. Scientific and technical information are scarce to support fertilizer recommendation aiming to replenish $\mathrm{N}$ exportation and to sustain mate productivity. Thus, this study aimed to evaluate the influence of $\mathrm{N}$ fertilization and harvest intervals on $\mathrm{N}$ and organic carbon $(\mathrm{CO})$ content in the soil and on mate productivity and $\mathrm{N}$ content. The experiment was conducted in São Mateus do Sul, Paraná state, Brazil, in a seven-year old mate plantation established on an Oxisol, where we evaluated the effect of $0,20,40,80,160$, and $320 \mathrm{~kg} \mathrm{ha}^{-1}$ of N, for harvest intervals of 12,18 , and 24 months. Nitrogen (NL) and CO (COL) in the labile and total (NT and COT) forms were determined in the soil at depths of $0-10,10-20$ and $20-40 \mathrm{~cm}$. Harvest consisted in the removal of $95 \%$ of the tree crown sprouted from the previous harvesting. The green material collected was evaluated individually for the components FO, GF and thick branches (GG), being FO+GF the commercial mate product (ECOM). We also evaluated the plant component relationships between green/dry weights (MV/MS), as well as the contents of N in FO, GF and GG. The positive effect of N fertilization on NL and COL contents in the soil was more expressive for the shortest harvesting interval, and was negative or null for the 24-month interval. Nitrogen doses increased the content of NT in the largest harvest interval and reduced the yield for 12 months; COT was not influenced by fertilization. We observed increased productivity with $\mathrm{N}$ doses, and the most significant responses occurred in longer harvest intervals. The interval of 12 months between harvests is insufficient for the plant recovery from the previous harvesting impacts. The 18-month interval is more recommendable because the plant is well nourished in N. Nitrogen does not affect the water content of the commercial green yerba mate, which is more affected by the time between harvests. The leaf $\mathrm{N}$ content between 33.0 and $37.0 \mathrm{~g} \mathrm{~kg}^{-1}$ may indicate well-nourished plants, regardless the harvest interval.

Keywords: Ilex paraguariensis; Efficiency of nutrient use; Harvesting handling; Organic matter of soil

\section{Introdução}

O nitrogênio é um dos elementos normalmente encontrado em maior concentração na parte vegetativa da maioria dos vegetais. Na erva-mate (Ilex paraguariensis St. Hil.), espécie arbórea cujo produto colhido é constituído principalmente por folhas e galhos finos (REISSMANN et al., 1985), o N é o nutriente mais exportado pela colheita. Contudo, apesar de ser uma cultura sulbrasileira centenária (CARVALHO, 2003) e que desempenha importante função socioeconômica para aproximadamente 700 mil pessoas (GAZETA GRUPO DE COMUNICAÇÕES, 1999), ainda não foram registrados avanços significativos no manejo nutricional da espécie. Isto tem refletido na produtividade brasileira de erva-mate, registrando-se entre 1990 a 2015, queda de 55 \% (IBGE, 2017). Por outro lado, estudos nas áreas de farmacologia e engenharia de alimentos têm demonstrado o grande potencial da espécie em benefícios para a saúde humana (BERTÉ et al., 2011; LANZETTI et al., 2012), fato que pode aumentar a demanda por matéria-prima.

A erva-mate era originalmente explorada em meio a florestas nativas em intervalos de 36 a 48 meses entre colheitas, tempo suficiente para que a ciclagem de nutrientes no ecossistema pudesse suprir as demandas nutricionais das esparsas plantas colhidas na área. Com a redução da área desses ervais, devido à supressão da vegetação nativa, iniciaram-se os plantios puros a pleno sol e o manejo dos nativos, dando origem a ervais de adensamento. Somado ao aumento de plantas por área, reduziu-se o intervalo de tempo entre colheitas, as quais, segundo Da Croce (1997), atualmente são realizadas anualmente ou com intervalos de 18 meses. Essas medidas, sem considerar a reposição dos nutrientes, corroboram para a queda da produtividade média brasileira de 17,3 $\mathrm{t} \mathrm{ha}^{-1}$, em 1990, para 7,7 t ha ${ }^{-1}$, em 2015 (IBGE, 2017), reduzindo acentuadamente sua rentabilidade.

Normalmente, o $\mathrm{N}$ é um dos nutrientes mais exportados pela colheita, especialmente quando o produto colhido é composto por folhas. Por outro lado, em virtude da multiplicidade de reações químicas e biológicas a que o $\mathrm{N}$ está sujeito no solo, os critérios para sua recomendação não estão bem estabelecidos (CANTARELLA; DUARTE, 2004), dificultando sua reposição adequada às culturas.

A maior parte do $\mathrm{N}$ no solo está na forma orgânica, em substâncias húmicas que compõem a matéria orgânica do solo (SILVA; MENDONÇA, 2007). A estreita relação entre o N e o C no solo tem estimulado inúmeros estudos com enfoque no aporte de resíduos orgânicos e sua dinâmica no solo e a disponibilidade de $\mathrm{N}$ para as plantas (CANTARELLA et al., 2008). Na cultura da erva-mate, a quantidade de galhos grossos resultantes da colheita pode superar $12 \mathrm{t} \mathrm{ha}^{-1} \mathrm{a}$ cada dois anos (SANTIN et al., 2015). Esse material é normalmente deixado na área, fato que justifica a necessidade de um 
melhor entendimento de sua decomposição e liberação de nutrientes como forma de melhoria da fertilidade do solo.

Os escassos experimentos com adubação nitrogenada têm demonstrado respostas positivas, apesar da espécie ocorrer naturalmente em solos de baixa fertilidade (CARVALHO, 2003). Os estudos pioneiros de Lourenço et al. (1997), no Brasil, testando $\mathrm{N}$ em erval com 12 anos de idade, indicam resposta positiva com produtividade anual de $15,0 \mathrm{t} \mathrm{ha}^{-1} \mathrm{com}$ aplicação anual de $186 \mathrm{~kg} \mathrm{ha}^{-1} \mathrm{de} \mathrm{N}$. Prat Kricun e Belingheri (1995) e Pandolfo et al. (2003) também relatam ganhos de produtividade de ervamate com adubação nitrogenada.

O estado nutricional da planta, obtido na faixa de ótimo crescimento, é um parâmetro normalmente utilizado e se correlaciona com características de crescimento e produtividade de culturas. No entanto, na erva-mate, a maioria dos trabalhos somente caracterizam nutricionalmente a planta. Ou seja, apenas relatam o teor de determinado nutriente na planta, sem indicar se este teor está ou não em nível adequado para a cultura. Teores foliares de $\mathrm{N}$ de plantas adultas de erva-mate variando desde 15,0 $\mathrm{g} \mathrm{kg}^{-1}$ (REISSMANN et al., 1999) até $46,9 \mathrm{~g} \mathrm{~kg}^{-1}$ (BRONDANI et al., 2008) têm sido relatados sem registros de sintomas de falta ou excesso. Variação essa, possivelmente, decorrente de diferenças entre solos, idade da planta, posição de coleta da folha na planta, época do ano de coleta e metodologia de determinação empregada. Isso não permite estabelecer uma faixa de teor foliar ótimo de $\mathrm{N}$ para essa cultura.

Neste contexto, objetivou-se avaliar a produtividade da erva-mate e seu estado nutricional, além do teor de $\mathrm{N}$ e $\mathrm{C}$ no solo em sua forma total e lábil, em função de diferentes intervalos de colheita e doses de nitrogênio.

\section{Material e método}

O experimento foi instalado em janeiro de 2009 no município de São Mateus do Sul - PR, localizado no segundo Planalto Paranaense (longitude $50^{\circ} 32^{\prime} 17^{\prime \prime} \mathrm{O}$ e latitude de $25^{\circ} 54^{\prime} 16^{\prime \prime} \mathrm{S}$ ) a $784 \mathrm{~m}$ de altitude, cujo clima é temperado $(\mathrm{Cfb})$ e a precipitação pluvial média anual varia de 1600 a 1800 mm (INSTITUTO AGRONÔMICO DO PARANÁ, 1994). O solo é um Latossolo Vermelho Distrófico (Tabela 1)

$\mathrm{Na}$ área, após remoção de parte da mata, permaneceram indivíduos adultos esparsos de ervamate nativa, araucária, imbuia e canelas. O erval foi estabelecido em julho de 2001 no espaçamento de $2 \mathrm{~m}$ x $2 \mathrm{~m}$, sem preparo de solo, apenas realizando abertura de cova, manualmente. A primeira colheita de erva-mate (poda de formação) foi efetuada 24 meses após o plantio a, aproximadamente, 1 $\mathrm{m}$ de altura do solo. As demais colheitas foram efetuadas a cada 18 meses, sendo a última em janeiro de 2009, no momento da instalação do experimento. Na área nunca foram realizadas calagem e adubações. Durante o experimento, a limpeza do erval foi realizada com roçadas mecânicas nos meses de setembro, janeiro e abril de cada ano.

Os tratamentos foram distribuídos em arranjo fatorial $(3 \times 6)$, em esquema de parcela subdividida, com três intervalos de colheita e seis doses de $\mathrm{N}$, sendo na parcela o intervalo de colheita e na subparcela as doses. Cada unidade experimental foi composta por 10 plantas úteis, com bordadura dupla. Quando na parcela ocorria a presença de indivíduos de araucária ou erva-mate nativa dentro da área útil, considerava-se uma bordadura de quatro metros (duas árvores de erva-mate plantadas) em relação a cada indivíduo estranho ao experimento, aumentado assim a área dessa parcela. Os tratamentos foram dispostos no delineamento blocos casualizados com cinco repetições.

Avaliaram-se colheitas com intervalos de 12, 18 e 24 meses e seis doses de nitrogênio, cuja fonte foi ureia; as doses consistiram em 0,20,40, 80,160 e $320 \mathrm{~kg} \mathrm{ha}^{-1} \mathrm{de}$ N. No momento da instalação do experimento, aplicou-se, superficialmente em área total, $1,0 \mathrm{t} \mathrm{ha} \mathrm{a}^{-1}$ de calcário dolomítico (32,4\% de $\mathrm{CaO}$ e $21,8 \%$ de $\mathrm{MgO}$, com PRNT de $82 \%$ ), conforme recomendação para a cultura (COMISSÃO DE QUÍMICA E FERTILIDADE DO SOLO, 2004). Como adubação complementar aplicaram-se $80 \mathrm{~kg}$ ha $^{-1}$ de $\mathrm{P}_{2} \mathrm{O}_{5}$ e $80 \mathrm{~kg} \mathrm{ha}^{-1}$ de $\mathrm{K}_{2} \mathrm{O}$, na forma de superfosfato triplo e cloreto de potássio, respectivamente. A dose de $80 \mathrm{~kg} \mathrm{ha}^{-1}$ de $\mathrm{N}$ correspondeu à reposição do nutriente exportado pela erva-mate na última colheita $\left(6,5 \mathrm{tha}^{-1}\right)$. 
A adubação complementar e as doses de $\mathrm{N}$ foram parceladas, sendo aplicadas superficialmente na área da projeção da copa e sem incorporação. Para as plantas colhidas 12 meses após a instalação do experimento, a aplicação das doses de $\mathrm{N}$ e a adubação complementar foram parceladas em duas vezes. Já as plantas colhidas aos 18 e 24 meses, após a instalação do experimento, receberam as adubações parceladas em três vezes iguais (Tabela 2). Quando na parcela ocorria a presença de algum indivíduo de erva-mate nativa ou de araucária, todos recebiam a mesma dose de nutrientes.

Após a instalação do experimento (Jan/2009), a colheita da erva-mate, para cada um dos intervalos de 12, 18 e 24 meses, foi realizada em jan/2010, jul/2010 e jan/2011, respectivamente. A colheita foi efetuada retirando-se aproximadamente $95 \%$ da massa verde da copa formada após a última colheita (jan/2009), da qual foi separada a erva-mate comercial (ECOM= folha+galho fino) do galho grosso (GG) e determinada a massa verde de ambos. O corte foi feito entre 10 a $15 \mathrm{~cm}$ acima da posição da última poda. Galhos com diâmetro, aproximadamente, menor que 7,0 $\mathrm{mm}$ foram considerados finos (GF) e os acima deste diâmetro como galhos grossos.

Tabela 1 - Teor de argila e propriedades químicas do solo, na profundidade de 0 a $20 \mathrm{~cm}$, no local do experimento.

Table 1 - Clay content and soil chemical properties at 0-20 $\mathrm{cm}$ depth on the experimental site.

\begin{tabular}{|c|c|c|c|c|c|c|c|c|}
\hline $\mathrm{CO}$ & $\mathrm{pH}$ & $\mathbf{A l}^{3+}$ & $\mathbf{H}+\mathbf{A l}$ & $\mathrm{CTC}_{\mathrm{pH} 7,0}$ & $\mathbf{V}$ & $\mathbf{m}$ & Argila & $\mathbf{K}$ \\
\hline $\mathrm{g} \mathrm{kg}^{-1}$ & $\mathrm{H}_{2} \mathrm{O}$ & \multicolumn{3}{|c|}{$-\ldots-\mathrm{cmol}_{\mathrm{c}} \mathrm{dm}^{-3}-\ldots-\ldots$} & \multicolumn{3}{|c|}{ 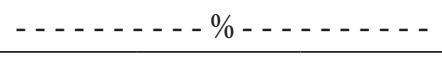 } & $\mathrm{mg} \mathrm{dm^{-3 }}$ \\
\hline 29,79 & 3,70 & 4,79 & 16,33 & 17,68 & 7,64 & 78,01 & 76 & 54,90 \\
\hline $\mathrm{Ca}^{2+}$ & $\mathrm{Mg}^{2+}$ & $\mathrm{P}$ & $\mathrm{S}-\mathrm{SO}_{4}^{2-}$ & $\mathrm{Cu}$ & $\mathrm{Zn}$ & $\mathrm{Fe}$ & $\mathrm{Mn}$ & $\mathrm{B}$ \\
\hline \multicolumn{2}{|c|}{$---\mathrm{cmol}_{\mathrm{c}} \mathrm{dm}^{-3}---$} & \multicolumn{7}{|c|}{$\ldots$} \\
\hline $\mathbf{0 , 8 7}$ & 0,34 & 1,50 & 7,56 & 13,10 & 2,50 & 71,00 & 29,00 & 0,53 \\
\hline
\end{tabular}

Fonte: Santin et al. (2019)

Extratores: Mehlich-1(P, K, Fe, Mn, Cu e Zn); KCl (Ca, Mg e Al); Calcinação e solução de $\mathrm{HCl}$ (B) e Fosfato de cálcio (S).

Tabela 2 - Parcelamento e época de aplicação da adubação e época de colheita da erva-mate em cada intervalo de colheita.

Table 2 - Subdivision and time of application of the fertilization and harvesting season of the yerba mate at each harvest interval.

\begin{tabular}{|c|c|c|c|c|c|c|c|c|}
\hline \multirow{3}{*}{ Experimento } & \multirow{3}{*}{$\begin{array}{c}\begin{array}{c}\text { Intervalo } \\
\text { de colheita }\end{array} \\
\text { Meses }\end{array}$} & \multicolumn{6}{|c|}{ Parcelamento e época de aplicação da adubação } & \multirow{3}{*}{$\begin{array}{c}\text { Colheita } \\
\text { Época }\end{array}$} \\
\hline & & \multicolumn{2}{|c|}{1 a parcela } & \multicolumn{2}{|c|}{$2^{\mathrm{a}}$ parcela } & \multicolumn{2}{|c|}{$3^{\mathrm{a}}$ parcela } & \\
\hline & & $\%$ dose & Época & $\%$ dose & Época & $\%$ dose & Época & \\
\hline \multirow{3}{*}{$\begin{array}{l}\text { Intervalo } \\
\text { de colheita }\end{array}$} & 12 & 50,0 & Jan/2009 & 50,0 & Set/2009 & ---- & ---- & $\operatorname{Jan} / 2010$ \\
\hline & 18 & 33,3 & Jan/2009 & 33,3 & Set/2009 & 33,3 & $\mathrm{Jan} / 2010$ & $\mathrm{Jul} / 2010$ \\
\hline & 24 & 33,3 & Jan/2009 & 33,3 & Set/2009 & 33,3 & Set $/ 2010$ & $\mathrm{Jan} / 2011$ \\
\hline
\end{tabular}

Fonte: Santin et al. (2019)

Antes da colheita, coletou-se na metade da altura da copa, uma amostra de aproximadamente $500 \mathrm{~g}$ de brotos de ECOM, separando-se as folhas (FO) dos GF para determinação da relação entre massa verde e seca e do teor de N (SOUZA et al., 2008). No momento da colheita, em cada parcela, retirou-se uma amostra representativa de GG, para essas mesmas determinações. Após quantificar 
a massa verde, o material foi lavado, seco a $65^{\circ} \mathrm{C}$ até peso constante, quantificada a massa seca, triturado em moinho tipo Wiley e, posteriormente, analisado quimicamente para N. A determinação do teor de $\mathrm{N}$ no tecido vegetal seguiu a metodologia de Bremner (1996).

Quantificou-se a produtividade de massa verde dos componentes: folha (FO), galho fino (GF), galho grosso $(\mathrm{GG})$ e erva-mate comercial $(\mathrm{ECOM}=\mathrm{FO}+\mathrm{GF})$. Para a ECOM foi também calculada a produtividade: 1 ) influenciada pelo intervalo entre colheitas (ECOM.PIC = produtividade na dose zero em cada intervalo de colheita); e 2) influenciada pela dose [ECOM.PID = produtividade incrementada pela adubação em cada intervalo de colheita (ECOM.PID = ECOM - ECOM.PIC)]. A eficiência de utilização de $\mathrm{N}$ (EUN), foi calculada pela razão entre massa seca de todos os componentes colhidos da planta (ECOM+GG) e o conteúdo do nutriente acumulado $\left(\mathrm{kg} \mathrm{kg}^{-1} \mathrm{de} \mathrm{N}\right)$ (BARROS et al., 1986). A relação entre peso de massa verde e seca (MV/MS) foi calculada para FO (FO.MV/MS), GF (GF.MV/ MS) e ECOM (ECOM.MV/MS).

No momento da colheita, em cada parcela, retirou-se uma amostra composta de solo proveniente de 15 amostras simples coletadas em três pontos na área da projeção da copa de cinco plantas, nas profundidades de 0-10, 10-20 e 20-40 cm. As amostras da camada de 0-10 cm foram coletadas com pá de corte, em uma faixa de $20 \mathrm{~cm}$ de largura por $3 \mathrm{~cm}$ de espessura. Nesses mesmos pontos foi coletado solo com trado holandês nas demais profundidades. As amostras foram secas ao ar, passadas em peneira com malha de $2 \mathrm{~mm}$ e analisadas para determinar o teor de nitrogênio lábil (NL) (BRANDANI, 2010 adaptado de SAHRAWAT, 1982), nitrogênio total (NT) (BREMNER, 1996), carbono orgânico lábil (COL) (BLAIR et al., 1995; SHANG; TIESSEN, 1997) e carbono orgânico total (COT) (YEOMANS; BREMNER, 1988; MENDONÇA; MATOS, 2005).

$\mathrm{Na}$ análise estatística, os fatores, como características do solo, intervalo de colheita, dose e profundidade, compuseram, respectivamente, parcela, subparcela e subsubparcela. Para as características da planta, o intervalo de colheita e dose compuseram, respectivamente, parcela e subparcela. Os dados foram submetidos à ANOVA a $5 \%$ de significância. As médias referentes ao efeito do intervalo de colheitas foram comparadas pelo teste de Tukey $(p<0,05)$ e o efeito das doses de $\mathrm{N}$, por análise de regressão, usando-se o software SISVAR (FERREIRA, 2008). Para NL, NT, COL e COT do solo, no desdobramento das interações entre o fator da parcela e subparcela e, ou, subsubparcela (profundidade), no sentido de avaliar o efeito da subparcela dentro da parcela e, ou, subsubparcela, adotou-se como erro o quadrado médio do resíduo combinado e o respectivo número de graus de liberdade, conforme Satterthwaite (1946).

\section{Resultados e discussão}

\section{Nitrogênio e carbono orgânico lábil e total do solo}

Os teores de $\mathrm{N}$ lábil (NL) e de $\mathrm{N}$ total (NT) foram influenciados pelo intervalo de colheita, pela dose de $\mathrm{N}$ e profundidade (Figura 1). Os teores de $\mathrm{C}$ orgânico lábil (COL) foram influenciados pela interação de intervalo de colheita e doses, variando com a camada de solo, enquanto o teor de $\mathrm{C}$ orgânico total (COT) somente foi influenciado pelo intervalo de colheita nas três profundidades (Figura 2).

A aplicação de $\mathrm{N}$ em plantios colhidos em intervalos de 12 meses elevou o teor de NL nas três camadas de solo analisadas. À medida que aumentou o intervalo de colheita, os efeitos das doses de $\mathrm{N}$ não foram significativos ou tenderam a reduzir o teor de NL no solo (Figura 1a, b, c). No intervalo de colheita de 18 meses, somente na menor profundidade o teor de NL aumentou com as doses de N. A amplitude de teores variou de $0,16 \mathrm{~g} \mathrm{~kg}^{-1}$, para o intervalo de 12 meses, na camada mais superficial, na dose de $254 \mathrm{~kg} \mathrm{ha}^{-1} \mathrm{de} \mathrm{N}$ (Figura 1a), a $0,03 \mathrm{~g} \mathrm{~kg}^{-1}$, no intervalo de 24 meses, na dose de $245 \mathrm{~kg} \mathrm{ha}^{-1}$ na camada mais profunda (Figura 1c). No intervalo de 12 meses, as doses influenciaram negativamente $o$ teor de NT (Figuras 1d, e, f). Nas três profundidades, o teor de NT foi maior no intervalo de 18 meses e menor no de 12 meses. Nos três intervalos de colheita, à medida que aumentou a profundidade do solo, ocorreu redução do teor de NT. 
A redução do teor de NT, pela adubação nitrogenada, no menor intervalo de colheita (Figuras $1 \mathrm{~d}, \mathrm{e}, \mathrm{f}$ ), pode estar relacionada ao estímulo da adubação na produção de biomassa de plantas espontâneas (encontradas em média intensidade, mas não mensuradas), que no decorrer de 12 meses ainda não teriam sido decompostas e mineralizadas. Além disso, o resíduo da colheita anterior (galho grosso) presente na área, material mais lignificado e de decomposição mais lenta, pode ter favorecido a imobilização de $\mathrm{N}$, reduzindo o teor de NT do solo. Para intervalos mais longos, parte do N imobilizado inicialmente já estaria mineralizado, aumentando o NT. A adição de N mineral favorece a atividade biológica do solo na decomposição do material orgânico, podendo haver imobilização de parte do N (GAMA-RODRIGUES et al., 2005; CAMARGO et al., 2008). No menor intervalo de colheita, a adubação nitrogenada pode ter estimulado a mineralização do $\mathrm{N}$ em resíduos menos lignificados, uma vez que estes são facilmente decompostos por microrganismos (SILVA; MENDONÇA, 2007), aumentado, portanto, o NL no solo. No entanto, o NL participa de uma pequena fração do NT do solo (CANTARELLA et al., 2008), sendo que seu aumento pouco influencia no NT.

\section{Figura 1 - Teores de $\mathbf{N}$ lábil $(\mathrm{a}, \mathrm{b}, \mathrm{c})$ e $\mathbf{N}$ total $(\mathrm{d}, \mathrm{e}, \mathrm{f})$ nas camadas de 0-10, 10-20 e 20-40 cm do solo influenciados por doses de $\mathrm{N}$ e intervalos de colheita de erva-mate.}

Figure 1 - Contents of labile N (a, b, c) and total N (d, e, f) at 0-10, 10-20 and 20-40 cm of soil influenced by $\mathrm{N}$ doses and harvest intervals of mate.

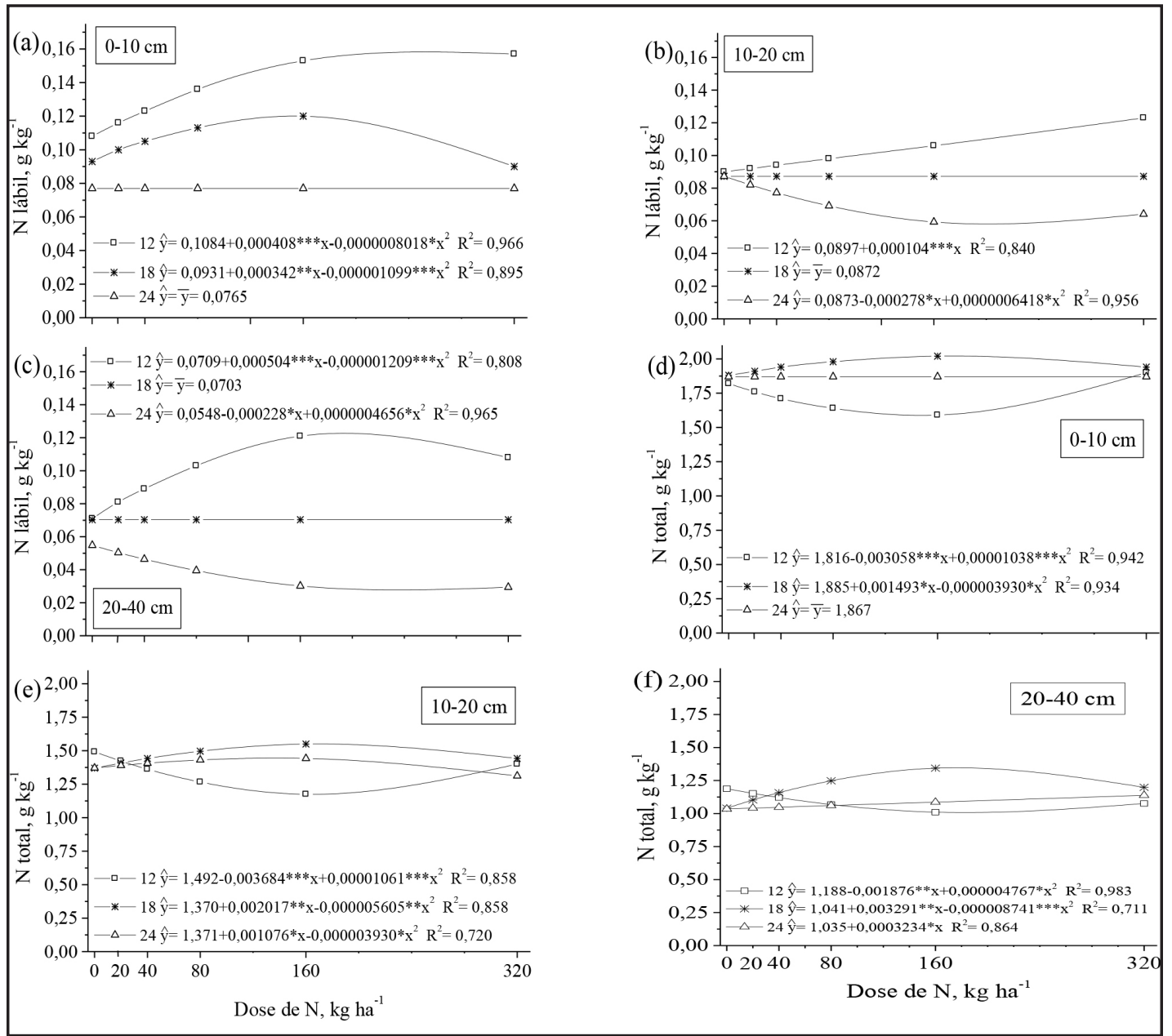

Fonte: Santin et al. (2019)

*, ** $\mathrm{e}^{* * *}$, respectivamente, significativo a 5, 1 e $0,1 \%$ de probabilidade.

${ }^{*},{ }^{* *}$, and ${ }^{* *}$, significant at 5,1 and $0.1 \%$ of probability, respectively. 
Os teores de COL nos três intervalos de colheita na profundidade de $0-10 \mathrm{~cm}$ foram significativamente influenciados pela aplicação de N (Figura 2a). Nas demais profundidades, esse comportamento foi observado somente para colheitas com intervalo de 12 e 18 meses (Figuras 2b, c). Com teores de 3,5; 3,0 e 3,4 $\mathrm{g} \mathrm{kg}^{-1}$ de COL detectados, respectivamente, nas doses de 181, 168 e $211 \mathrm{~kg} \mathrm{ha}^{-1}$ de $\mathrm{N}$, da menor para a maior profundidade, o intervalo de colheita de 12 meses apresentou os maiores valores. A contribuição positiva da adubação nitrogenada no aumento de COL também foi verificada por Vieira et al. (2007), em culturas anuais em sistema de cultivo mínimo no sul do Brasil, assim como Brandani (2010), nos teores de N e C lábeis do solo na decomposição dos resíduos da colheita de eucalipto deixados no campo em diferentes regiões do Brasil.

O teor de COT não foi influenciado pela aplicação de $\mathrm{N}$. O teor médio de $41,7 \mathrm{~g} \mathrm{~kg}^{-1} \mathrm{na}$ camada de 0-10 cm de profundidade do solo foi semelhante entre os intervalos de colheita. $\mathrm{O}$ maior teor de COT $\left(36,4 \mathrm{~g} \mathrm{~kg}^{-1}\right)$, detectado no solo, na profundidade de $10-20 \mathrm{~cm}$, corresponde ao intervalo de 18 meses, e o menor $\left(28,4 \mathrm{~g} \mathrm{~kg}^{-1}\right)$, na profundidade de $20-40 \mathrm{~cm}$, no intervalo de colheita de 24 meses (Figura 2d). Aventa-se a hipótese que estes dois valores sejam decorrentes do aporte de material orgânico, provavelmente de raízes, nessas camadas.

Figura 2 - Teor de carbono orgânico lábil (COL) (a, b, c) e total (COT) (d) nas camadas de 0-10 cm (a), 10-20 cm (b) e 20-40 cm (c) de solo influenciado por doses de $\mathrm{N}$ e intervalos de colheita de 12, 18 e 24 meses em plantio de erva-mate.

Figure 2 - Content of organic carbon, labile (COL) (a, b, c) and total (COT) (d), at depths of 0-10 $\mathrm{cm} \mathrm{(a)} 10-20 \mathrm{~cm} \mathrm{(b)} \mathrm{and} 20$ to $40 \mathrm{~cm}$ (c) in soil influenced by $\mathrm{N}$ doses and harvest intervals of 12 , 18 and 24 months in mate plantation.

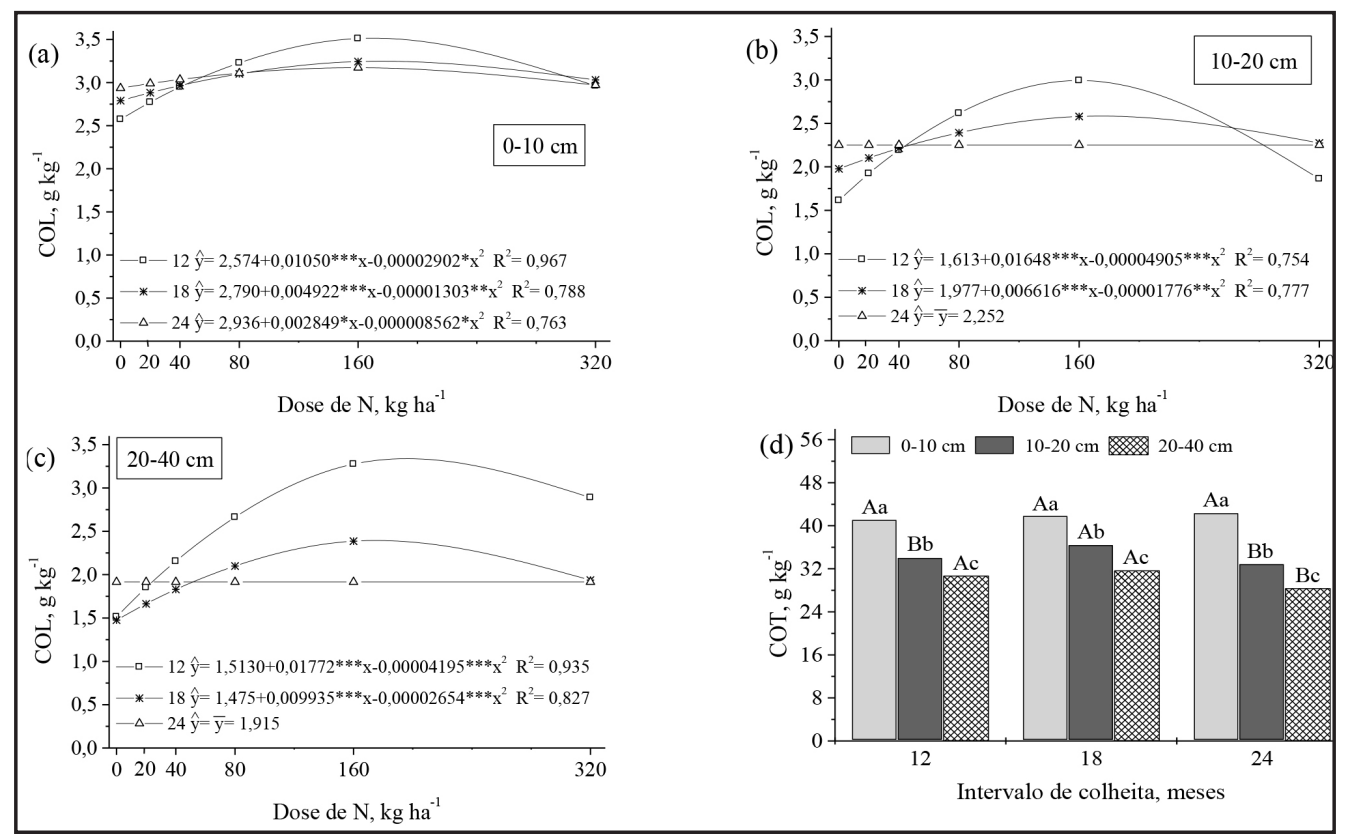

Fonte: Santin et al. (2019)

${ }^{*},{ }^{* *} \mathrm{e}^{* * *}$, respectivamente, significativo a 5, 1 e 0,1\% de probabilidade. Médias seguidas por uma mesma letra maiúscula não diferem estatisticamente entre intervalos de colheita e médias seguidas por mesma letra minúscula não diferem estatisticamente entre profundidades $(\mathrm{p}<0,05)$ pelo teste de Tukey.

${ }^{*},{ }^{* *}$, and ${ }^{* * *}$, respectively significant at 5,1 and $0.1 \%$ of probability. Means followed by the same capital letter do not differ statistically between the harvest intervals and means followed by the same lowercase letter do not differ statistically between depths $(\mathrm{p}<0.05)$ by Tukey test.

Essa possibilidade é reforçada pelo aumento do teor de COL, no mesmo intervalo de colheita, em todas as profundidades do solo (Figura 2a, b, c). Nos maiores intervalos de colheita, 
à medida que ocorreu maior crescimento da copa das plantas, a incidência de luz nas entrelinhas foi reduzida, restringindo a produção e estimulando a mineralização dos resíduos das plantas espontâneas existentes nos primeiros meses após a poda da erva-mate. Deve-se, ainda, considerar a renovação do sistema radicular das plantas de erva-mate, principalmente na contribuição do COL do solo. Para períodos mais longos entre colheitas, as raízes mortas já teriam passado pelos processos de imobilização e mineralização, o que pode ter contribuído para o menor aumento do COL e maior de NT nos intervalos de 18 e 24 meses. Como a atividade microbiana no solo pode ser fortemente estimulada pelo N (GAMA-RODRIGUES et al., 2005; CAMARGO et al., 2008), a decomposição e mineralização de resíduos mais lábeis, na maior dose de $\mathrm{N}$, podem ter sido favorecidas. Isso pode ter contribuído para a redução do teor de COL na maior dose de N, principalmente nos menores intervalos de colheita, nas três profundidades do solo (Figura 2a, b, c).

A ausência e, ou, baixa variação do teor de COT verificado durante o período experimental era esperada. Normalmente, em sistemas conservacionistas já estabelecidos, a alteração do teor de COT torna-se pouco perceptível em períodos curtos de tempo (SILVA; MENDONÇA, 2007). Contudo, a redução do COT, principalmente nas camadas mais profundas, no intervalo entre colheitas de 24 meses, indica que para intervalos mais longos, as doses testadas não foram suficientes para manter os teores de C nesse solo. Piccolo et al. (2004) constataram que o solo sob erva-mate, com mais de 50 anos de cultivo, apresentou grande redução dos estoques de C, e após 10 anos da introdução de capim-elefante (Pennisetum purpureum Schumach) entre as linhas de plantio, ocorreu aumento não somente do C, mas também da fertilidade do solo. Isso comprova que coberturas vegetais contribuem para o aporte de $\mathrm{C}$ no sistema.

\section{Produtividade e estado nutricional de $\mathbf{N}$ da erva-mate}

A adubação nitrogenada promoveu aumento da produção de massa verde dos componentes das plantas avaliados (Figura 3), com exceção do GG para colheita com intervalo de 12 meses (Figura 3c). Entretanto, a resposta de produtividade dos componentes ocorreu de forma diferenciada entre intervalos de colheita. No intervalo de 24 meses, a produtividade máxima de FO, GF, GG e erva-mate comercial (ECOM), respectivamente de 20,7, 5,1, 12,5 e 25,9 $\mathrm{t} \mathrm{ha} \mathrm{a}^{-1}$, ocorreu ao aplicar-se a maior dose de N. No intervalo de 12 meses, a maximização da produtividade de FO, GG e ECOM ocorreu, respectivamente, nas doses de 203, 182 e $197 \mathrm{~kg} \mathrm{ha}^{-1}$ de N. A maximização da produtividade de todos os componentes da copa, para intervalo de 18 meses, ocorreu em doses intermediárias às de 12 e 24 meses (Figura 3). Com a produtividade máxima do intervalo de 24 meses, detectada na maior dose para todos os componentes, indica, que neste intervalo de colheita, a dose de $320 \mathrm{~kg} \mathrm{ha}^{-1}$ de $\mathrm{N}$ foi insuficiente para que a planta demonstrasse seu potencial produtivo.

A resposta à adubação nitrogenada, mesmo que o solo apresentasse alto teor de CO $(29,8$ $\mathrm{g} \mathrm{kg}^{-1}$ ), demonstra que a demanda da planta por $\mathrm{N}$ é elevada e, ou, que o nutriente estaria em formas muito estáveis de $\mathrm{CO}$ no solo. Em ambientes preservados, o CO pode estar estabilizado fisicamente em micro e macroagregados (PAUSTIAN et al., 2000), restringindo o acesso de microrganismos ao substrato (DAVIDSON; JANSSENS, 2006; TANEVA; GONZALEZ-MELLER, 2008) reduzindo sua mineralização e, consequentemente, a disponibilidade do N. Neste contexto, na cultura da erva-mate já estabelecida, na qual o revolvimento do solo não é realizado, a existência de altos teores de $\mathrm{CO}$ não significa que as plantas terão adequado suprimento de $\mathrm{N}$, sendo necessária a aplicação de adubo nitrogenado.

A adubação nitrogenada mostrou-se de grande importância na recuperação da planta após a colheita (Figura 4b). A produtividade de ECOM sem adubação (ECOM.PIC) (Figura 4a) no intervalo de colheita de 24 meses foi duas vezes maior aos demais intervalos, indicando a necessidade de tempo mais longo entre colheitas para que a planta recomponha sua copa, quando não adubada. Com a adubação nitrogenada, quando avaliada a interação entre intervalo 
de colheita e dose de $\mathrm{N}$ na obtenção da produção máxima de ECOM incrementado pela dose (ECOM.PID), as plantas colhidas no intervalo de 18 meses mostraram crescimento $54 \%$ superior àquelas do intervalo de 12 meses, sendo a de 18 meses $\left(6,1 \mathrm{t} \mathrm{ha}^{-1}\right)$ mais próxima à de 24 meses $(8,3$ $\left.\mathrm{t} \mathrm{ha}^{-1}\right)$, comparativamente à de 12 meses $\left(2,8 \mathrm{t} \mathrm{ha}^{-1}\right)$ (Figura $\left.4 \mathrm{~b}\right)$.

Figura 3 - Produtividade de massa verde de folhas (a), galhos finos (b), galhos grossos (c) e erva-mate comercial (d) em plantio de erva-mate com intervalos entre colheitas de 12, 18 e 24 meses submetidos à adubação nitrogenada.

Figure 3 - Mass productivity of green leaves (a), thin branches (b), thick branches (c) and commercial mate (d) in plantation with 12,18 and 24 months harvest intervals submitted to nitrogen fertilization.

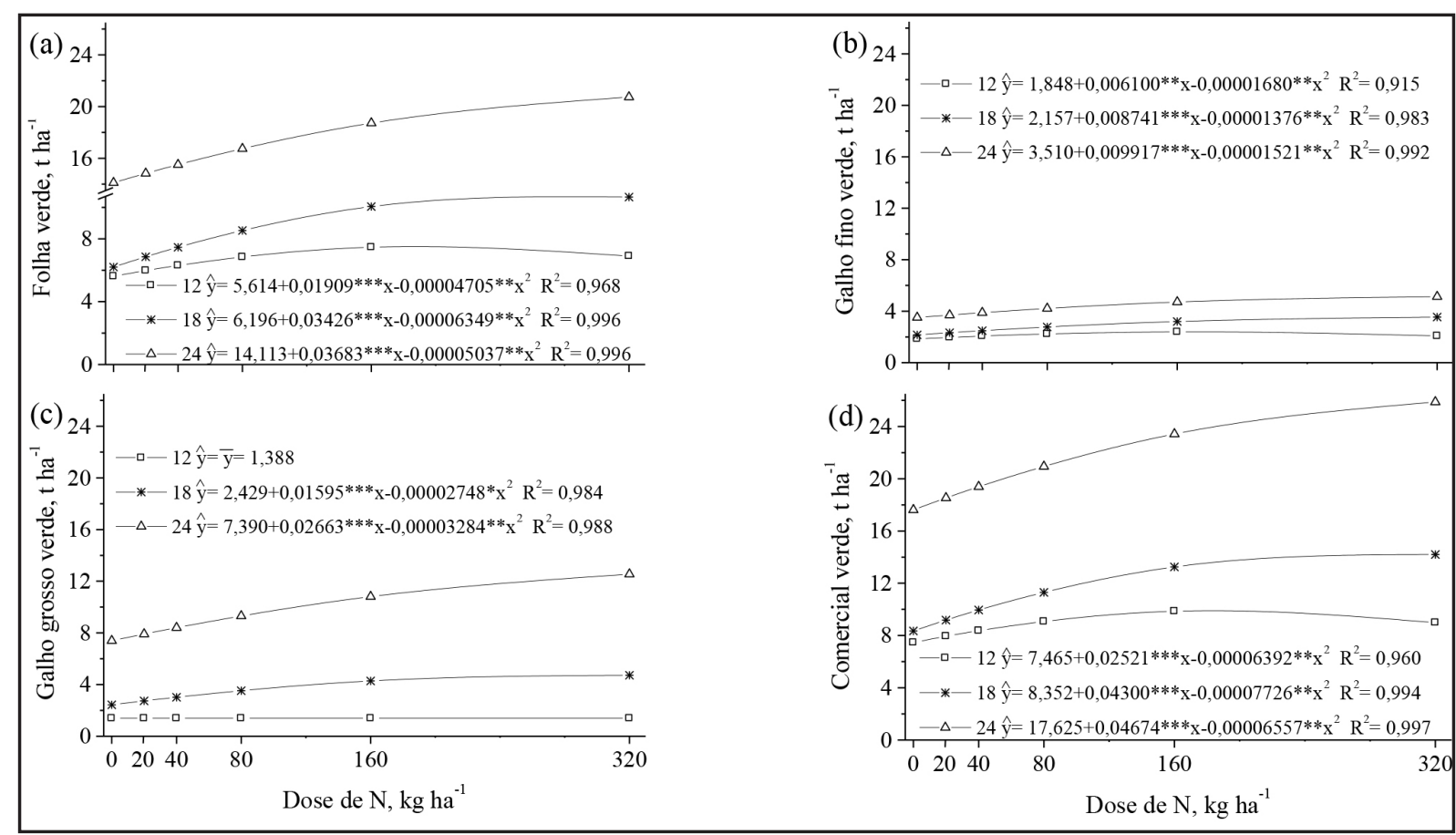

Fonte: Santin et al. (2019)

*, ${ }^{* *} \mathrm{e}^{* * *}$, significativo a 5,1 e $0,1 \%$ de probabilidade, respectivamente.

${ }^{*},{ }^{* *}$, and ${ }^{* * *}$, significant at 5,1 and $0.1 \%$ of probability, respectively.

A menor eficiência de uso do N (EUN) ocorrida para o intervalo de 12 meses (Figura 4c) também sinaliza que para a cultura da erva-mate, quando na colheita removem-se $95 \%$ das folhas, devem ser evitadas colheitas com intervalos curtos. A EUN reduziu com o aumento das doses nos três intervalos de colheita. A EUN mínima variou de 34,7 a $45,1 \mathrm{~kg} \mathrm{~kg}^{-1}$, respectivamente, nas colheitas com 12 e 24 meses de intervalos.

A relação entre massa verde e seca (MV/MS) de ECOM só foi influenciada pelo intervalo de colheita. A menor relação MV/MS foi observada no maior intervalo de colheita (Figura 4d). Contudo, a relação ECOM/GG foi maior no intervalo de 12 meses e menor no de 24 meses (Figura 4e). Considerando as doses de 198, 278 e $320 \mathrm{~kg} \mathrm{ha}^{-1}$, nas quais ocorreu a máxima produtividade de ECOM, respectivamente, nos intervalos de 12, 18 e 24 meses (Figura 3d), observou-se decréscimo na relação de ECOM/GG na mesma ordem, isto é, de 6,9, 3,0 e 2,1. Ou seja, quanto maior o intervalo de colheita, maior será o gasto de energia para produzir GG em detrimento da produção de ECOM.

A resposta expressiva da erva-mate à adubação nitrogenada, na colheita com intervalo 
de 24 meses, e pouco pronunciada na de 12 meses, demonstra que o fator tempo entre colheitas atua fortemente na quantidade de $\mathrm{N}$ requerida pela cultura. Outros fatores, como textura do solo (LOURENÇO et al., 1997) e densidade de plantas (PRAT KRICUN; BELINGHERE, 1995), também podem refletir na resposta ao N. Aumento na produtividade de erva-mate em resposta à adubação nitrogenada foi verificado por Lourenço et al. (1997) somente em solo de textura média. Na Argentina, Prat Kricun e Belinghere (1995) verificaram que, quando a densidade de plantas esteve entre 1900 e 4000 planta ha $^{-1}$, mesmo com dose de $300 \mathrm{~kg} \mathrm{ha}^{-1}$ de $\mathrm{N}$, o aumento da produtividade foi linear. Contudo, em plantios com densidade entre 1100 a 1480 plantas ha ${ }^{-1}, 100$ $\mathrm{kg} \mathrm{ha}^{-1}$ de $\mathrm{N}$ foram suficientes para maximizar a produtividade. Após cinco de colheitas anuais sucessivas, em plantio de nove anos, Pandolfo et al. (2003) constataram produtividade média anual de 13,6 t ha ${ }^{-1}$, com aplicação anual de $153 \mathrm{~kg} \mathrm{ha}^{-1}$ de $\mathrm{N}$. A máxima produtividade em plantios de primeira colheita obtida com aplicação de $52,5 \mathrm{~kg} \mathrm{ha}^{-1}$ de N (RIBEIRO et al., 2008), comparada à resposta positiva a altas doses (PRAT KRICUN; BELINGHERE, 1995; LOURENÇO et al., 1997) e constatada neste trabalho (variação entre 180 a $320 \mathrm{~kg} \mathrm{ha}^{-1}$ ) sugere que a demanda por $\mathrm{N}$ pela erva-mate seja bem diferente da de culturas florestais tradicionais. Em espécies florestais, como o eucalipto, a resposta máxima ao $\mathrm{N}$ ocorre na fase jovem (até 3 anos) e, na fase intermediária e adulta, é pequena ou nula (PULITO, 2009). Para erva-mate, a resposta ao $\mathrm{N}$ pode ser branda na fase jovem, porém, bem pronunciada na fase de produção. Isso decorre do fato da necessidade da planta recuperar a copa em ciclos curtos, devido à colheita da folha, a qual possui, naturalmente, maior concentração de $\mathrm{N}$. Podas que garantam a permanência de 20 a $30 \%$ da massa de folha na copa da planta deverão reduzir o impacto da colheita, por permitir fotossíntese plausível para início da brotação da copa.

A baixa ECOM.PIC verificada nos intervalos de colheita de $12\left(7,2 \mathrm{t} \mathrm{ha}^{-1}\right)$ e $18\left(8,2 \mathrm{t} \mathrm{ha}^{-1}\right)$ meses, quando comparada à de 24 meses $\left(17,6 \mathrm{t} \mathrm{ha}^{-1}\right.$ ) (Figura 4a) demonstra que períodos curtos entre colheitas, sem adubação nitrogenada, são insuficientes para que a planta se recomponha do impacto da remoção da copa. A poda provoca um desequilíbrio entre folhas e raízes, requerendo uma reação compensatória da planta (MILANO; DALCIN, 2000), o que ocorreu somente na colheita de 24 meses. Neste caso, a baixa produtividade estaria muito mais relacionada à limitada taxa fotossintética, proporcionada pela pequena área foliar, do que a restrições nutricionais (EPSTEIN; BLOOM, 2004), hipótese suportada pela boa ECOM.PIC no intervalo de 24 meses. Contudo, a máxima ECOM.PID do intervalo de 18 meses, próxima à máxima ECOM.PID de 24 meses (Figura $4 \mathrm{~b}$ ), sugere que a adubação nitrogenada contribuiu para a recuperação de plantas submetidas à colheita de 18 meses de intervalo, mas o mesmo efeito não foi constatado na colheita com 12 meses. Outros manejos de colheita, em que a remoção da copa seja menos drástica, possivelmente, permitiriam que a planta se recuperasse mais rapidamente e a resposta à adubação seria mais expressiva nos três intervalos de colheita.

A redução expressiva da relação entre os componentes ECOM/GG, à medida que os intervalos de colheita aumentaram e para intervalos de 18 e 24 meses à medida que aumentaram as doses de $\mathrm{N}$, demonstra que altas produtividades de ECOM dependem de grande investimento de energia pela planta para produção de GG. Ao comparar plantios com cinco anos estabelecidos com mudas propagadas via sexuada com assexuada, com colheitas a cada 24 meses, Santin et al. (2015) constataram ECOM/GG entre 1,0 e 1,2, relação bem abaixo dos 6,9, 3,0 e 2,1, respectivamente, nos intervalos de 12, 18 e 24 meses na dose de máxima produtividade de ECOM que ocorreram nesse estudo.

Na dose de máxima produtividade de ECOM (Figura 3d), a menor EUN (34,9 $\left.\mathrm{kg} \mathrm{kg}^{-1} \mathrm{de} \mathrm{N}\right)$, para todos os componentes colhidos, foi observada no intervalo de 12 meses, quando comparada à de $18\left(42,2 \mathrm{~kg} \mathrm{~kg}^{-1}\right.$ de N) e 24 meses $\left(45,1 \mathrm{~kg} \mathrm{~kg}^{-1} \mathrm{de} \mathrm{N}\right)$ (Figura 4c). Em condições nutricionais limitantes, normalmente com pequenas doses de fertilizantes, as plantas aumentam a absorção de nutrientes e a produção de forma linear (KEULEN, 1982). Em condição de alta disponibilidade de nutrientes é comum as plantas absorvê-los além de sua demanda, consequentemente, reduzindo a EUN (EPSTEIN; BLOOM, 2004). Na erva-mate, além da disponibilidade do nutriente, intervalos 
de colheitas mais curtos também reduziram a EUN.

Figura 4 - Produtividade de erva-mate comercial (ECOM) influenciada pelo intervalo de colheita (ECOM.PIC) (a) e pela dose (ECOM.PID) (b); eficiência de utilização do nutriente (EUN) (c); relação, entre massa verde e seca (MV/MS) de ECOM (d) e entre ECOM e galho grosso (GG) verde (e) em plantio de erva-mate com intervalos entre colheitas de 12, 18 e 24 meses submetidos à adubação nitrogenada.

Figure 4 - Productivity of commercial mate (ECOM) influenced by harvest interval (ECOM. PIC) (a) and doses of N (ECOM.PID) (b); N use efficiency (EUN) (c); relationship between greens and dry mass (MMV/ MMS) of ECOM (d) and between ECOM and thick branch (GG) (e) in mate plantation with 12,18 and 24 month-harvest intervals submitted to $\mathrm{N}$ fertilization.

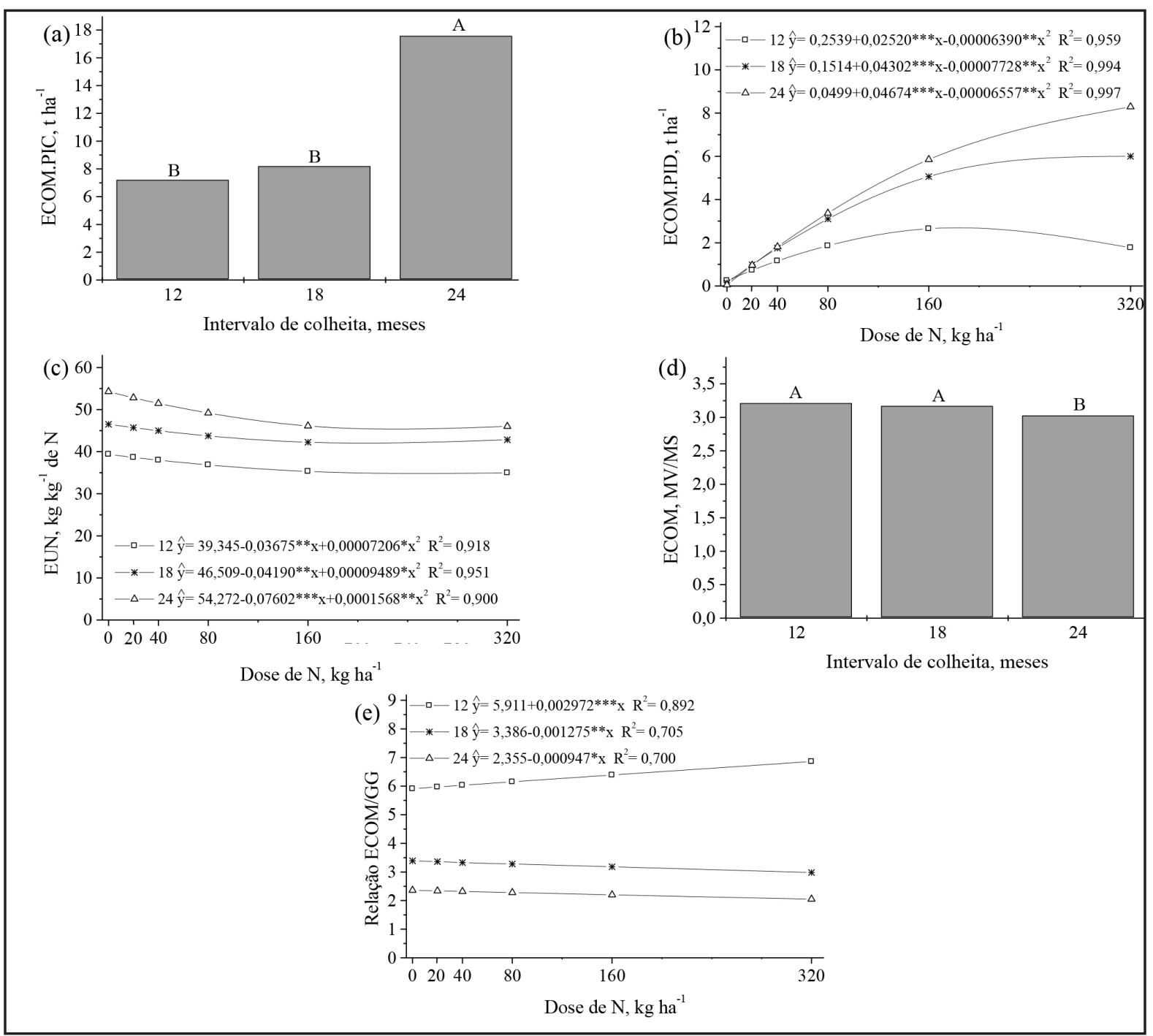

Fonte: Santin et al. (2019)

** $\mathrm{e}^{* * *}$, significativo a 1 e $0,1 \%$ de probabilidade, respectivamente. Média dos três intervalos de colheita; e médias seguidas por uma mesma letra na coluna não diferem estatisticamente $(\mathrm{p}<0,05)$ pelo teste de Tukey.

** and ${ }^{* * *}$ significant at 1 and $0.1 \%$ of probability, respectively. Average of three harvest intervals, and means followed by the same letter in the column do not differ statistically $(\mathrm{p}<0.05)$ by Tukey test.

O teor de $\mathrm{N}$ no tecido vegetal diferiu entre os vários componentes da copa, em função da 
dose e do intervalo de colheita (Figura 5a, b, c). Na FO, o teor máximo de N, 37,0, 37,2 e 34,0 g kg-1, ocorreu, respectivamente, nas doses de 232, 241 e $262 \mathrm{~kg} \mathrm{ha}^{-1}$ e nos intervalos de 12, 18 e 24 meses entre colheitas (Figura 5a). No GF, somente no intervalo de 24 meses a adubação influenciou no teor de $\mathrm{N}$, com 15,4 $\mathrm{g} \mathrm{kg}^{-1}$ na maior dose aplicada (Figura 5b). No GG, o teor máximo de $\mathrm{N}$ foi de 8,1 e $7,6 \mathrm{~g} \mathrm{~kg}^{-1}$, respectivamente, nos intervalos de 12 e 18 meses (Figura 5c).

Figura 5 - Teor de $\mathrm{N}$ nas folhas (FO) (a), galhos finos (GF) (b) e galhos grossos (GG) (c); e conteúdo de $\mathrm{N}$ na erva-mate comercial (ECOM) (d) e no GG (e) em plantio de erva-mate com intervalos entre colheitas de 12, 18 e 24 meses submetidos à adubação nitrogenada.

Figure 5 - N content in leaves (FO) (a), thin (GF) (b) and thick branches (GG) (c), and N content of commercial mate (ECOM) (d) and in GG (e) in mate plantation with 12, 18 and 24 monthharvest intervals submitted to $\mathrm{N}$ fertilization.

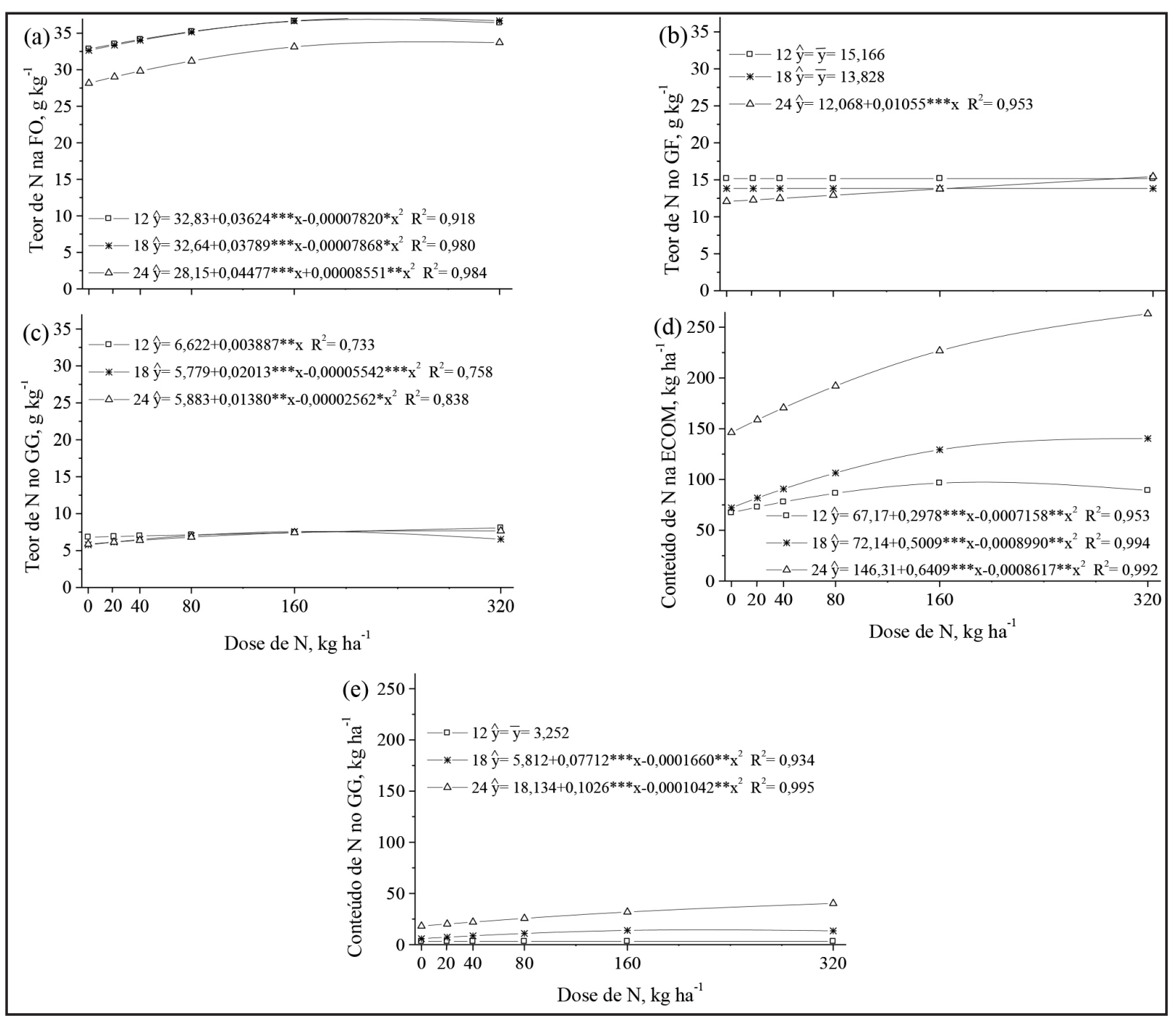

Fonte: Santin et al. (2019)

*, ** $\mathrm{e}^{* * *}$, significativo a 5,1 e $0,1 \%$ de probabilidade, respectivamente.

${ }^{*},{ }^{* *}$, and ${ }^{* * *}$, significant at 5,1 and $0.1 \%$ of probability, respectively.

O conteúdo de $\mathrm{N}$, que indica a exportação do nutriente da área pela colheita, determinado para os componentes ECOM e GG, foi diferente nos componentes analisados e, principalmente, na ECOM, entre intervalos de colheita (Figura 5d, e). Na ECOM, o conteúdo máximo de 98, 142 
e $263 \mathrm{~kg} \mathrm{ha}^{-1}$ de $\mathrm{N}$ ocorreu, respectivamente, nos intervalos de 12, 18 e 24 meses (Figura 5d). No GG, somente as doses alteraram o conteúdo de $\mathrm{N}$ nos intervalos de colheita de 18 e 24 meses, com valor de 14,8 e 40,3 $\mathrm{kg} \mathrm{ha}^{-1}$ de $\mathrm{N}$, respectivamente (Figura 5e).

Considerando-se a dose de $\mathrm{N}$ para a máxima produtividade de ECOM em cada intervalo de colheita (Figura 3d), o teor foliar de $\mathrm{N}$ de 36,9, 37,1 e 33,7 $\mathrm{g} \mathrm{kg}^{-1}$ (Figura 5a) está acima do verificado por outros autores, como 18,8 $\mathrm{g} \mathrm{kg}^{-1}$ (REISSMANN et al., 1997) e 29,1 $\mathrm{g} \mathrm{kg}^{-1}$ (PANDOLFO et al., 2003). No entanto, o teor foliar de $\mathrm{N}$ na erva-mate pode apresentar grande variação. Na caracterização nutricional de 16 cultivos de diferentes locais e idades no Paraná, Reissmann et al. (1999) constataram teor foliar de $\mathrm{N}$ variando de 15,0 a $36,6 \mathrm{~g} \mathrm{~kg}^{-1}$, que, juntamente com os 46,9 $\mathrm{g} \mathrm{kg}^{-1}$ verificados por Brondani et al. (2008), demonstram a magnitude da variação, o que dificulta definir uma faixa ideal do teor foliar do nutriente para essa cultura. O menor teor foliar de $\mathrm{N}$ para colheita de 24 meses e a variação nos valores observados em diferentes trabalhos sugerem que o teor crítico para a cultura deve ser definido para cultivos segundo faixas de idade, tipo de cultivo (pleno sol ou sombreado), estação do ano, intervalo entre colheitas e material genético.

O teor de N no GF e GG que variou, respectivamente, de 13,8 a 15,4 e 7,0 a $7,7 \mathrm{~g} \mathrm{~kg}^{-1}$ (Figuras 5b, c), se assemelha aos teores entre 9,4 a 12,5 e 5,5 a 7,8 g kg-1 obtidos por Campos (1991). Apesar de o GG ser o componente da copa com menor teor de N, quando a produção na área é considerável, o conteúdo de $\mathrm{N}$ (Figura 5e) se torna expressivo, assim como ocorreu com o intervalo de colheita de 24 meses (Figura 3c e 5e). Em manejos de colheita em que o GG é retirado da área, somando-se a ECOM, com colheitas com 18 e 24 meses seriam exportados da área respectivamente, 156 e $304 \mathrm{~kg} \mathrm{ha}^{-1}$ de N. Na década de 1980, quando o sistema brasileiro de colheita da erva-mate era baseado no extrativismo, Reissmann et al. (1985) já alertavam para a expressiva exportação de nutrientes da área pela colheita. Atualmente, mesmo que o sistema de cultivo tenha privilegiado maior densidade de plantas por área e, concomitantemente, reduzido o tempo entre colheitas (DA CROCE, 1997), a maioria da produção brasileira de erva-mate é oriunda de sistemas nos quais não se prevê a reposição dos nutrientes exportados pela colheita. Nota-se que, apesar da alta dose aplicada $\left(320 \mathrm{~kg} \mathrm{ha}^{-1} \mathrm{de} \mathrm{N}\right)$, a diferença entre entrada e saída seria de apenas $16 \mathrm{~kg} \mathrm{ha}^{-1}$ de $\mathrm{N}$ na colheita de 24 meses. Diante deste resultado é explicável a atual produtividade média brasileira de $7,7 \mathrm{t} \mathrm{ha}^{-1}$ (IBGE, 2017) e que, sem a devida reposição nutricional, não é possível garantir um sistema sustentável e de alta produtividade.

\section{Conclusões}

O teor de COT no solo não é influenciado pela adubação nitrogenada, mas tende a reduzir quando a colheita é realizada com intervalo de 24 meses. A adubação nitrogenada tem efeito positivo no teor de NL e COL do solo para ervais com intervalos de colheita menores e negativo ou nulo para o intervalo de 24 meses. Por outro lado, a adubação nitrogenada aumenta o teor de NT no solo nos maiores intervalos e reduz nos menores intervalos de colheita.

Intervalo de colheita de 12 meses é insuficiente para a planta recompor a copa removida pela colheita, e colheitas com intervalos de 18 meses são recomendadas somente quando as plantas estão nutridas adequadamente. Para colheitas com intervalo de 12 meses recomendamse doses menores que $200 \mathrm{~kg} \mathrm{ha}^{-1}$ de $\mathrm{N}$. Já para colheitas com intervalo de 18 meses, as doses de $\mathrm{N}$ devem estar abaixo de $280 \mathrm{~kg} \mathrm{ha}^{-1}$, e com intervalos de 24 meses as doses podem superar $320 \mathrm{~kg}$ $\mathrm{ha}^{-1}$ do nutriente aplicado entre cada colheita.

Teor foliar de $\mathrm{N}$ entre 33,0 e $37,0 \mathrm{~g} \mathrm{~kg}^{-1}$ pode indicar plantas bem nutridas neste nutriente para cultivos em fase de produção, independentemente do intervalo de colheita. Quando as colheitas são realizadas em intervalos de 18 e 24 meses com a retirada de galhos grossos, acréscimos de 10 e $15 \%$ na dose de adubação nitrogenada devem ser previstos para evitar perda de produtividade. 


\section{Agradecimentos}

À Agropecuária Vier Ltda e à Baldo S.A. de São Mateus do Sul - PR, à Embrapa CNPF de Colombo - PR, ao Departamento de Solos da UFV de Viçosa - MG e ao CNPq que possibilitaram a realização do trabalho.

\section{Referências}

BARROS, N. F. et al. Classificação nutricional de sítios florestais - Descrição de uma metodologia. Revista Árvore, Viçosa, MG, v. 10, p. 112-120, 1986.

BERTÉ, K. et al. Yerba mate Ilex paraguariensis A. St.-Hil. Phytothérapie, Paris, v. 9, p. 180-184, 2011.

BLAIR, G. J. et al. Soil carbon fractions, based on their degree of oxidation, and the development of a carbon management index for agricultural systems. Australian Journal of Agricultural Research, Victoria, v. 46, p. 1459-1466, 1995.

BRANDANI, C. B. Decomposição de resíduos de eucalipto e efluxo de C- $\mathrm{CO}_{2}$ em solos em diferentes locais do Brasil. 2010. Dissertação (Mestrado em Solos e Nutrição de Plantas) Universidade Federal de Viçosa, Viçosa, MG, 2010.

BREMNER, J. M. Nitrogen total. In: SPARKS, D. L. (ed.). Methods of soil analysis. Madison: American Society of Agronomy, 1996. p. 1085-1121.

BRONDANI, G. E. et al. Distribuição de NPK em um povoamento de Ilex paraguariensis A. St.-Hil. Floresta, Curitiba, v. 38, p. 267-275, 2008.

CAMARGO, F. A. O. et al. Nitrogênio orgânico do solo. In: SANTOS, G. A. et al. Fundamentos da matéria orgânica do solo. 2. ed. Porto Alegre: Metrópole, 2008. p. 87-99.

CAMPOS, M. A. A. Balanço de biomassa e nutrientes em povoamentos de Ilex paraguariensis.: avaliação na safra e na safrinha. 1991. Dissertação (Mestrado em Ciência do Solo) - Universidade Federal do Paraná, Curitiba, 1991.

CANTARELlA, H.; DUARTE, A. P. Manejo da fertilidade do solo para a cultura do milho. In: GALVÃO, J. C. C.; MIRANDA, G. V. (ed.). Tecnologia de produção de milho. Viçosa, MG: UFV, 2004. p. 139-182.

CANTARELLA, H. et al. Matéria orgânica do solo e disponibilidade de N as plantas. In: SANTOS, G. A. et al. (ed.). Fundamentos da matéria orgânica do solo. 2. ed. Porto Alegre: Metrópole, 2008. p. 581-595.

CARVALHO, P. H. R. Espécies arbóreas brasileiras. Brasília: EMBRAPA Informação tecnológica; Colombo: EMBRAPA Florestas, 2003. 1039 p.

COMISSÃO DE QUÍMICA E FERTILIDADE DO SOLO. Manual de adubação e calagem para os Estados do Rio Grande do Sul e de Santa Catarina. 10. ed. Porto Alegre: SBCS; UFRGS, 2004. $400 \mathrm{p}$.

DA CROCE, D. M. Poda de erva-mate: novos métodos desenvolvidos pela EPAGRI. In: CONGRESSO SUL-AMERICANO DE ERVA MATE, 1.; REUNIÃO TÉCNICA DO CONE SUL SOBRE A CUlTURA DA ERVA MATE, 2., 1997, Curitiba. Anais [...]. Colombo: EMBRAPA; CNPF, 1997. p. 351-357.

DAVIDSON, E. A.; JANSSENS, I. A. Temperature sensitivity of soil carbon decomposition and feedbacks to climate change. Nature, London, v. 440, p. 165-173, 2006.

EPSTEIN, E.; BLOOM, A. J. Nutrição mineral de plantas: princípios e perspectivas. 2. ed. 
Londrina: Planta, 2004. 403 p.

FERREIRA, D. F. Sisvar: um programa para análises e ensino de estatística. Revista Científica Symposium, Lavras, v. 6, n. 2, p. 36-41, jul./dez. 2008.

GAMA-RODRIGUES, E. F. et al. Nitrogênio, carbono e atividade da biomassa microbiana do solo em plantações de eucalipto. Revista Brasileira de Ciência do Solo, Viçosa, MG, v. 29, p. 893-901, 2005.

GAZETA GRUPO DE COMUNICAÇÕES. Anuário Brasileiro da Erva-mate 1999. Santa Cruz do Sul: Pallotti, 1999. 64 p.

INSTITUTO AGRONÔMICO DO PARANÁ. Cartas climáticas básicas do Estado do Paraná. Londrina: IAPAR, 1994. 49 p.

IBGE. Produção agrícola municipal. [2017]. Disponível em: <https://sidra.ibge.gov.br/ Tabela/106\#resultado>. Acesso em: $01 \mathrm{dez} .2017$.

KEULEN, H. V. Graphical analysis of annual crop response to fertilizer application. Agricultural Systems, Essex, v. 9, p. 113-126, 1982.

LANZETTI, M. et al. Ready-to-drink matte ${ }^{\circledR}$ tea shows anti-inflammatory and antioxidant propertieson a cigarette smoke exposure model. Food Research International, Ontário, v. 48, p. 798-801, 2012.

LOURENÇO, R. S. et al. Avaliação de níveis de nitrogênio sobre a produção de erva-mate (Ilex paraguariensis St. Hil.) em Fernandes Pinheiro, PR, em Latossolo Vermelho Escuro. Boletim de Pesquisa Florestal, Colombo, v. 34, p. 75-98, 1997.

MENDONÇA, E. S.; MATOS, E. S. Matéria orgânica do solo: métodos de análises. Viçosa, MG: [s. n.], 2005. 77 p.

MILANO, M.; DALCIN, E. Arborização de vias públicas. Rio de Janeiro: Light, 2000. 206 p.

PANDOLFO, M. C. et al. Resposta da erva-mate (Ilex paraguariensis St. Hil.) à adubação mineral e orgânica em um Latossolo Vermelho alumino férrico. Ciência Florestal, Santa Maria, v. 13, p. 37-45, 2003.

PAUSTIAN, K. et al. Management options for reducing $\mathrm{CO}_{2}$ emissions from agricultural soils. Biogeochemistry, Philadelphia, v. 48, p. 147-163, 2000.

PICCOLO, G. A. et al. Organic carbon fractions in a yerba mate plantation on a subtropical Kandihumult of Argentina. Geoderma, Amsterdam, v. 123, p. 333-341, 2004.

PRAT KRICUN, S. D.; BELINGHERI, L. D. Aplicación de nitrógeno em plantaciones de yerba mate con diferentes densidades. In: WINGE, H. et al. (ed). Erva-mate biologia e cultura no cone sul. Porto Alegre: Ed. Universidade UFRGS, 1995. p. 73-79.

PULITO, A. P. Resposta à fertilização nitrogenada e estoque de nitrogênio biodisponível em solos usados para plantações de Eucalyptus. 2009. Dissertação (Mestrado em Recursos Florestais) - Universidade de São Paulo, Piracicaba, 2009.

REISSMANN, C. B. et al. Avaliação da exportação de macronutrientes pela exportação da erva-mate. In: SEMINÁRIO SOBRE ATUALIDADES E PERSPECTIVAS FLORESTAIS, 1985, Curitiba. Anais [...]. Curitiba: EMBRAPA; CNPF, 1985. p. 128-139. Tema: Silvicultura da ervamate (Ilex paraguariensis St. Hil).

REISSMANN, C. B. et al. Chemical composition of Ilex paraguariensis St. Hil. Under different management conditions in seven localities of Paraná State. Brazilian Archives of Biology and Technology, Curitiba, v. 42, p. 187-194, 1999.

REISSMANN, C. B. et al. Production and foliar N, P, K, Ca and Mg levels in erva-mate (Ilex 
paraguariensis St. Hil.), related to increasing base saturation levels. Brazilian Archives of Biology and Technology, Curitiba, v. 40, p. 241-249, 1997.

RIBEIRO, M. M. et al. Nutrição da erva-mate com sulfato de amônio. Cerne, Lavras, v. 14, p. 204$211,2008$.

SANTIN, D. et al. Sobrevivência, crescimento e produtividade de plantas de erva-mate produzidas por miniestacas juvenis e por sementes. Ciência Florestal, Santa Maria, v. 25, n. 3, p. 571-579, 2015.

SATTERTHWAITE, F. E. An approximate distribution of estimates of variance components. Biometrics Bulletin, Washington, v. 2, p. 110-114, 1946.

SHANG, C.; TIESSEN, H. Organic matter lability in a tropical Oxisol: evidence from shifting cultivation, chemical oxidation, particle size, density, and magnetic fractionations. Soil Science Society of America Journal, Baltimore, v. 162, p. 795-807, 1997.

SILVA, I. R.; MENDONÇA, E. S. Matéria orgânica do solo. In: NOVAIS, R. F. et al. (ed). Fertilidade do solo. Viçosa, MG: SBCS, 2007. p. 275-374.

SOUZA, J. L. M. et al. Exportação de nutrientes foliares em diferentes tipos de poda na cultura da erva-mate. Scientia Agraria, Curitiba, v. 9, n. 2, p. 177-185, 2008.

TANEVA, L.; GONZALEZ-MELER, M. A. Decomposition kinetics of soil carbon of different age from a forest exposed to 8 years of elevated atmospheric $\mathrm{CO}_{2}$ concentration. Soil Biology \& Biochemistry, Berlin, v. 40, p. 2670-2677, 2008.

VIEIRA, F. C. B. et al. Carbon management index based on physical fractionation of soil organic matter in an Acrisol under long-term no-till cropping systems. Soil \& Tillage Research, Valdivia, v. 96, p. 195-204, 2007.

YEOMANS, J. C.; BREMNER, J. M. A rapid and precise method for routine determination of organic carbon in soil. Communications in Soil Science and Plant Analysis, New York, v. 19, p. 1467-1476, 1988. 